\title{
ABORDAGEM AO NEOINSTITUCIONALISMO E SEUS DESDOBRAMENTOS EM ANÁLISES SOBRE O LEGISLATIVO MUNICIPAL 123
}

\author{
Marcus Vinicius Teixeira Valle
}

\section{RESUMO}

A proposta deste artigo é analisar o neoinstitucionalismo e a forma pela qual este é tratado pela literatura da ciência política e na esfera municipal brasileira, assim como os estudos que abordam o comportamento legislativo de acordo com a perspectiva neoinstitucionalista e sua influência no âmbito municipal. Isso será feito de acordo com a análise de algumas literaturas que apontam para o fato de a atividade parlamentar na esfera municipal ter sua relevância, mas não ser tratada da mesma maneira que as outras esferas (estadual e nacional). Até porque boa parte das pesquisas desenvolvidas no Brasil (sobre a representação política a partir da atividade legislativa) é voltada para estudos que abordam, em sua maioria, as esferas nacional ou estadual.

Palavras-chave: representação política; neoinstitucionalismo; vereador; esfera municipal.

\begin{abstract}
The purpose of this paper is to analyze the neoinstitutionalism and the way in which it is treated by the literature of political science and in the Brazilian municipal level, as well as the studies that approach the legislative behavior according to the neoinstitutionalist perspective and its influence in the municipal scope. This will be done according to the analysis of the literature that point to the fact that parliamentary activity in the municipal level has its relevance, but not to be treated in the same way as the other levels of governance (state and national). Even because most of the research carried out in Brazil (on political representation from legislative activity) is focused on studies that mostly address the national or state level.
\end{abstract}

Keywords: political representation; neo-institutionalism; councilor; municipal level.

\section{RESUMEN}

La propuesta de este artículo es analizar el neoinstitucionalismo y la forma en que éste es tratado por la literatura de la ciencia política y en la esfera municipal brasileña, así como los estudios que abordan el comportamiento legislativo de acuerdo con la perspectiva neoinstitucionalista y su influencia en el ámbito municipal. Esto se hará de acuerdo con el análisis de algunas literaturas que apuntan al hecho de que la actividad parlamentaria en la esfera municipal tiene su relevancia, pero no se trata de la misma manera que las otras esferas (estatal y nacional). Porque la mayoría de las investigaciones desarrolladas en Brasil (sobre la representación política a partir de la actividad legislativa) están dirigidas a estudios que abordan, en su mayoría, las esferas nacional o estatal.

Palabras-clave: Representación política; neoinstitucionalismo; concejales; esfera municipal.

\section{INTRODUÇÃO}

Nos últimos anos, os estudos sobre comportamento legislativo cresceram muito, ganhando cada vez mais destaque no meio acadêmico, o que possibilitou um avanço nas discussões sobre o tema em questão. Deve-se ressaltar que eles deram mais atenção a questões do processo legislativo nas esferas federal e estadual, procurando compreender a

\footnotetext{
${ }^{1}$ Enviado: $31 / 03 / 2017$

Aceito: 30/06/2017

${ }^{2}$ Este artigo faz parte do primeiro capítulo intitulado "Uma abordagem sobre o conceito de representação política e a forma como se apresenta nos estudos sobre o legislativo municipal" da Dissertação de Mestrado produzida pelo autor.

${ }^{3}$ DOI: $10.5380 /$ recp.v8i1.51554

${ }^{4}$ Possui graduação em Ciências Sociais pela Universidade Federal Fluminense (2008), Mestre em Ciências Sociais pelo Programa de Pós-Graduação em Ciências Sociais (PPGCS) da Universidade Federal Rural do Rio de Janeiro (2014).
} 
relação entre os Poderes Executivo e Legislativo, além da maneira como se dá o processo de organização da Câmara dos Deputados ou das assembleias legislativas.

No que diz respeito ao Legislativo na esfera municipal, contudo, não houve o mesmo interesse. Ao contrário, percebemos que as análises do funcionamento, da organização e do papel do Poder Legislativo no município avançaram muito pouco no mesmo período. Esse aspecto é apresentado da seguinte forma:

\begin{abstract}
Não são muitos os estudos que se concentram na dimensão local da presente experiência democrática no Brasil. Qualquer que seja a abordagem ou o objeto da análise, o foco quase sempre incide na esfera nacional. Entretanto, a política local está longe de ser irrelevante para o sistema democrático do país. Do ponto de vista institucional, a federação brasileira tende a ser um sistema bastante descentralizado - ainda que não se tenha completado o processo de transferência de atribuições e competências para os municípios. Do ponto de vista do processo político é, sobretudo no âmbito local, mas não exclusivamente, que emergem formas inovadoras de ação governamental, gestão pública e participação dos cidadãos. (ALMEIDA; CARNEIRO 2003, p. 125).
\end{abstract}

Kerbauy (2005, p. 339) também afirma que as análises do "comportamento legislativo" ficaram restritas à atuação nas esferas federal (Câmara dos Deputados) e estadual (assembleias legislativas). Em seu trabalho, ela questiona se as conclusões acerca do comportamento de deputados federais e estaduais poderiam ser estendidas aos legislativos municipais. Isso decorre do fato de não haver muitas pesquisas que procuram abordar e destacar o poder local no Brasil, assim como a esfera legislativa municipal.

A pouca atenção dada aos municípios, mencionada acima, contrasta com o novo cenário instituído pela Constituição de 1988, que, ao colocá-los como entes federados, ampliou sua importância nas relações políticas no Brasil. Seguimos, dessa forma, "uma tendência internacional de tornar relevantes as unidades subnacionais de governo e que acabou promovendo um processo de descentralização em termos administrativos" (KERBAUY 2005, p. 338).

Diante isso, a proposta deste artigo é analisar a perspectiva neoinstitucionalista e a maneira pela qual ela é tratada pela literatura da ciência política na esfera municipal brasileira. Isso será feito de acordo com a análise de algumas literaturas que apontam para o fato de que a atividade parlamentar na esfera municipal tem sua relevância, mas não é tratada da mesma maneira que as outras esferas (estadual e nacional). Até porque boa parte das pesquisas desenvolvidas no Brasil (sobre a atividade legislativa) é voltada para estudos que abordam, em sua maioria, as esferas nacional ou estadual. 
VALLE, M. V. T. Abordagem ao neoinstitucionalismo e seus desdobramentos nas análises que se apresentam nos estudos sobre o Legislativo Municipal

A partir desses apontamentos, o artigo está dividido em: (i) a discussão conceitual sobre o desenvolvimento do neoinstitucionalismo no Brasil e sua influência nas pesquisas desenvolvidas acerca do legislativo brasileiro e (ii) a análise e a descrição de pesquisas que abordaram esse tema no nível municipal, o comportamento dos vereadores e os estudos legislativos na esfera local a partir das abordagens metodológicas que foram desenvolvidas em suas pesquisas. Assim, a proposta do texto é demonstrar que as condições políticas e institucionais presentes nas pesquisas têm como objetivo a valorização política da esfera municipal.

\section{A INFLUÊNCIA DO NEOINSTITUCIONALISMO NAS ANÁLISES DOS ESTUDOS QUE ABORDAM A ESFERA LEGISLATIVA NO BRASIL}

O neoinstitucionalismo vem sendo a teoria mais utilizada para estudar o comportamento do Legislativo no Brasil. Essa abordagem está associada à ideia de que, por meio da institucionalização de padrões de ação e de processos de negociação no contexto de organizações, é possível influenciar processos políticos.

Outro aspecto a ser destacado é que as pesquisas voltadas para o estudo do Congresso brasileiro orientam-se principalmente por dois modelos teóricos estadunidenses da teoria positiva dos estudos legislativos, advindos do neoinstitucionalismo de escolha racional que analisou o comportamento dos parlamentares no Congresso dos Estados Unidos na década de 1970. Assim, as análises realizadas pelos cientistas políticos brasileiros foram orientadas por esse paradigma.

Segundo Hall e Taylor (2003), as perspectivas neoinstitucionalistas

\footnotetext{
[...] se desenvolveram como reação contra as perspectivas behavioristas, que foram influentes nos anos 60 e 70. Todas elas buscam elucidar o papel desempenhado pelas instituições na determinação de resultados sociais e políticos. As imagens que apresentam do mundo político, contudo, são muito diferentes. (HALL; TAYLOR 2003, p. 194).
}

Os autores ainda ressaltam que o novo institucionalismo se apresenta a partir de três métodos de análise das instituições e dos atores políticos. Esses modelos são identificados como:

(a) institucionalismo histórico, em que as instituições são analisadas de acordo com a trajetória dos atores políticos, contextualizada de forma local, acarretando um tipo de 
desenvolvimento histórico associado aos processos políticos e às relações entre atores que estão articuladas a circunstâncias sociais, políticas e econômicas;

(b) institucionalismo da escolha racional, formado a partir de estudos sobre o comportamento dos parlamentares no interior do Congresso norte-americano, demonstra que as instituições procuram equacionar dilemas de ação coletiva, na medida em que interferem no comportamento dos atores e que se restringem aos possíveis cálculos estratégicos nas ações políticas desses atores. Essa proposta de análise leva em conta os indivíduos e suas escolhas segundo as "regras do jogo" em que estão inseridos;

(c) institucionalismo sociológico, originado da teoria das organizações, parte do princípio de que as formas e práticas institucionais não são constituídas com o objetivo de ter eficácia, mas por sua institucionalização, que se dá a partir das práticas culturais, ou pela rotina das organizações modernas (tais como os partidos políticos, os sindicatos e os órgãos governamentais).

Ainda de acordo com os autores, essas distinções serviram como referência e formaram um aparato teórico-metodológico para as análises sobre a relação entre o Executivo e o Legislativo. O que se verifica tanto na produção internacional quanto na brasileira é uma predileção dos cientistas políticos pelo institucionalismo da escolha racional nos estudos sobre o Legislativo, seguindo as definições de Hall e Taylor (2003).

Diante dessa exposição acerca da perspectiva neoinstitucionalista, devemos ressaltar sua influência sobre os estudos voltados para a "dinâmica do sistema político brasileiro", posterior à promulgação da Constituição de 1988. De acordo com Torrens (2015), a teoria neoinstitucionalista se propõe analisar "as instituições, relações entre Executivo e Legislativo, padrão de distribuição dos poderes de agenda, estabilidade política, sistemas de governo e governabilidade" (TORRENS 2015, p. 30).

Torrens (2015) ainda cita quatro trabalhos importantes que têm como foco a explicação das decisões sociais nas instituições, mais do que nas preferências dos atores políticos, como Anastasia (1997), Santos (1997), Limongi e Figueiredo (2004) e Morais (2008).

Outro ponto que devemos destacar é o que Silva (2013) apresenta sobre a transformação, em termos metodológicos e conceituais, a respeito dos estudos legislativos. Isso é observado quando "o Poder Legislativo havia sido interpretado durante muitos anos (até meados da década de 1980) apenas como um resultado das escolhas feitas pelos eleitores em meio às regras do sistema eleitoral e do sistema partidário" (SILVA 2013, p. 40). Ainda devemos ressaltar que os estudos sobre o Legislativo se debruçaram sobre a análise da 
VALLE, M. V. T. Abordagem ao neoinstitucionalismo e seus desdobramentos nas análises que se apresentam nos estudos sobre o Legislativo Municipal

representatividade parlamentar sob a pluralidade da sociedade brasileira durante esse tempo, como se verifica a seguir:

O Legislativo, em específico, seguia como grande alvo de críticas pelos analistas por não possuir a capacidade de refletir as vontades dos amplos segmentos sociais diversificados regionalmente no país, sendo o lugar das negociações clientelistas e práticas fisiológicas de políticos essencialmente preocupados em legislar para garantirem a manutenção de seus redutos eleitorais. (SILVA 2013, p. 40).

Essa perspectiva de análise foi passível de críticas e revisões, levando ao neoinstitucionalismo, que tem como proposta a compreensão das instituições políticas como fatores que influenciam as ações dos atores que as compõem. Dessa forma, devemos entender que as instituições interferem na dinâmica do Legislativo, ou seja, acabam influenciando a atuação e o comportamento dos parlamentares. De acordo com Torrens (2015, p. 2), essas premissas do neoinstitucionalismo se apresentam da seguinte maneira:

(a) As instituições estruturam e ordenam o comportamento político dos atores. São o foco central na análise da vida política;

(b) Os marcos institucionais nos quais os indivíduos agem apresentam impacto decisivo sobre o comportamento dos atores inseridos no sistema político;

(c) As instituições têm duas ordens de procedimentos: os formais e os informais, sendo os primeiros passíveis de ser descritos oficialmente, enquanto os segundos poderiam ser determinados por meio de análises contínuas acerca do comportamento dos atores em seu cotidiano no interior da instituição.

Outro elemento que podemos identificar, de acordo com Barbosa, é que categorias como "federalismo, sistema eleitoral de lista aberta, desempenho eleitoral, ideologia, sistema partidário (fragmentação e multipartidarismo) e posição política" adquiriram posição privilegiada "nos trabalhos dos cientistas políticos" (BARBOSA 2014b, p. 15). Quando se analisa o parlamento nacional, constata-se que esses são elementos relevantes para uma predominância da arena eleitoral sobre a congressual ou legislativa (AMES 2003; MAINWARING 2001). Isso pode ser percebido, por exemplo, na análise de Mainwaring, quando afirma em seu

[...] argumento básico [...] que o sistema eleitoral brasileiro contribuiu para minar os esforços de construção de partidos políticos mais efetivos. Vários aspectos da legislação eleitoral brasileira não têm paralelo (ou têm pouco) no mundo, e nenhuma outra democracia dá aos políticos tanta autonomia vis-àvis seus partidos. Essa legislação eleitoral reforça o comportamento individualista dos políticos e impede a construção partidária. Os graus extremamente baixos de fidelidade e disciplina partidária encontrados nos 
principais partidos (à exceção dos vários partidos de esquerda) são tolerados e estimulados por essa legislação. (MAINWARING 1991, p. 35).

A relação que se estabelece entre o presidencialismo (sistema de governo), o federalismo (organização institucional do Estado) e o sistema proporcional de lista aberta (processos e regras) possibilitou uma multiplicidade de modos e meios pelos quais o agente político procura alcançar os postos de governo. Apesar dessa complexidade, pode-se observar, de acordo com a perspectiva neoinstitucionalista, a influência de tais instituições sobre a composição das carreiras políticas dos parlamentares. Um exemplo disso é o princípio proporcional que se estabeleceu para a escolha dos membros do Poder Legislativo em todos os níveis de disputa federal, estadual e municipal.

Também deve ser ressaltado o voto nominal, que permite ao eleitor optar não só por um partido, mas também pelo candidato de sua preferência. Os votos nominais são dados aos candidatos de um mesmo partido ou coligação de partidos. Ainda sobre esse ponto, o sistema eleitoral brasileiro para eleições de membros do Poder Legislativo ocorre pelo sistema da representação proporcional de lista aberta. A distribuição do poder parlamentar pelos partidos se dá de forma proporcional, ou seja, os partidos só alcançam cadeiras na Câmara se atingirem o quociente eleitoral ${ }^{5}$.

Devemos destacar que as instituições como o presidencialismo, o federalismo e o sistema eleitoral, na perspectiva da teoria neoinstitucionalista, determinam, conformam e influenciam o comportamento de eleitores e candidatos.

Torrens (2015) afirma que Anastasia (1997) chama a atenção para o fato de que esses "mecanismos institucionais de interlocução com segmentos da sociedade organizada" atuam como importantes canais de interação entre os processos de participação e de representação política e têm como consequência a interferência na agenda do Executivo no que diz respeito à condução de políticas públicas (TORRENS 2015, p. 29). Isso pode ser verificado nas palavras de Anastasia, quando afirma que:

Essas novas formas de interlocução com a sociedade civil permitem aos participantes a vocalização de suas preferências, a explicitação e o tratamento dos pontos de divergência ou a dissensão quanto às políticas em pauta e a construção de um consenso, via deliberação política, que informa a produção legislativa nos temas em discussão. Além disso, elas permitem que os

\footnotetext{
${ }^{5} \mathrm{O}$ quociente eleitoral é calculado dividindo-se o número de votos válidos (nominais e de legenda) pelo número de vagas disponíveis por cada unidade da Federação. Para se conhecer o número de cadeiras que o partido ou a coligação alcançou, é necessário dividir o número de votos válidos recebido pelo partido ou coligação pelo quociente eleitoral. Os mais votados de um partido ou coligação são eleitos desde que o partido ou coligação tenha atingido o quociente eleitoral. Um candidato pode receber uma excelente votação, mas não ser eleitor porque seu partido não atingiu o quociente eleitoral.
} 
VALLE, M. V. T. Abordagem ao neoinstitucionalismo e seus desdobramentos nas análises que se apresentam nos estudos sobre o Legislativo Municipal

participantes possam monitorar e acompanhar as ações de seus representantes no decorrer do processo legislativo. (ANASTASIA, 1997, p. 26).

A partir desses aspectos, os processos políticos democráticos podem ser analisados por meio de diversos artifícios. A variedade de situações exibidas pela dinâmica política autoriza o recurso a diferentes modelos analíticos. Em relação a isso, o atual sistema político brasileiro se constitui em um elemento desafiante para os trabalhos desenvolvidos pelos cientistas políticos que procuram pesquisar as carreiras políticas e legislativas.

A promulgação da Constituição de 1988 promoveu uma reorganização institucional e suscitou o desenvolvimento de uma ampla agenda de pesquisa nas ciências sociais brasileiras. Vários cientistas políticos se interessaram pela compreensão e pelo entendimento das consequências trazidas pelos arranjos da nova Carta, que acarretou o fortalecimento e a ampliação da esfera legislativa, embora, segundo Figueiredo e Limongi, isso não tenha levado ao enfraquecimento do Executivo, como se verifica na afirmação do autor:

\begin{abstract}
A Constituição de 1988 consagrou duas tendências aparentemente conflitantes: de um lado, devolveu ao Poder Legislativo muitos dos poderes que ele tinha ao longo da experiência democrática anterior; de outro, manteve a maioria dos poderes legislativos de que foi dotado o Executivo ao longo do período autoritário. Assim, como veremos a seguir, o Executivo acaba por comandar o processo legislativo. A estruturação interna do Legislativo responde a essa preponderância. As funções que o colégio de líderes acaba por desempenhar devem ser vistas como as respostas possíveis de um Congresso envolvido nesse tipo de relação. (FIGUEIREDO, LIMONGI 2004, p. 48)
\end{abstract}

Nesse momento, as análises dos pesquisadores eram voltadas para a compreensão da dinâmica da nova ordem democrática a partir de avaliações descritivas e metodológicas, sustentadas por dados empíricos. Para Figueiredo e Limongi (2004), essas análises procuraram abordar de forma privilegiada o estudo do processo decisório e das relações entre Executivo e Legislativo como fonte alternativa ao entendimento do sistema político brasileiro.

$\mathrm{O}$ autor ainda ressalta que os estudos legislativos se constituem em uma subárea consolidada no interior do estudo da política estadunidense. Seu estabelecimento no Brasil se dá pela influência dessa literatura. Nesse sentido, a ampliação de pesquisas sobre estudos legislativos vem se destacando como um dos principais campos da ciência política brasileira. Essas análises passaram a privilegiar o estudo do processo decisório e das relações entre Executivo e Legislativo como uma forma de se entender o do sistema político brasileiro. De acordo com Silva:

As pesquisas acerca do funcionamento das instituições políticas brasileiras podem ser consideradas dentre as que mais avanços teóricos e metodológicos obtiveram na ciência política nacional desde meados da década de 1990. 
Enquanto parte desse avanço houve a consolidação de um campo em específico, designado estudos do legislativo no Brasil. (SILVA, 2013, p. 4).

Ainda para Silva (2013), os tipos de produção acadêmica se propuseram analisar três subáreas, que se dividiram em: 1) partidos políticos; 2) dinâmicas de eleição/reeleição e de recrutamento político e carreiras parlamentares; 3) relação entre Executivo e Legislativo. Levamos em conta que essas análises eram voltadas para o funcionamento e a organização do Legislativo nacional.

Tais análises tiveram como proposta demonstrar que instituições políticas se organizam com o propósito de produzir governabilidade. Diante disso, surgiu uma nova perspectiva sobre as relações entre o Executivo e o Legislativo, que se destacou no meio acadêmico e fixou a governabilidade como um novo foco de análise, baseada na estrutura do próprio processo decisório e do impacto no comportamento parlamentar e no desempenho governamental. Nesse ponto, a dimensão institucional é colocada como um elemento central nas relações entre o Executivo e o Legislativo, principalmente na correlação de forças partidárias e institucionais para promover governabilidade.

No que se refere às análises do comportamento parlamentar, os políticos têm seus interesses particulares e agem de acordo com eles. Suas decisões políticas nem sempre são voltadas para o bem comum. Há até a possibilidade de executar ações desse tipo, mas tentam maximizar sua utilidade, e toda ação no parlamento é sempre orientada para sua reeleição, eleição para um cargo no Executivo estadual ou municipal ou sua indicação para um ministério.

De acordo com Limongi (1994), o comportamento do parlamentar é individualista. Ainda sobre esse aspecto comportamental, o autor ressalta que:

\footnotetext{
Os Novos Institucionalistas mantêm a premissa de Arrow e McKelvey: as preferências individuais não interferem na escolha social. E acrescentam que a escolha social depende diretamente da intervenção das instituições. $\mathrm{O}$ seu entendimento se baseia nas análises calcadas no pluralismo ou na análise sistêmica à la David Easton. Para estas perspectivas, o papel desempenhado pelas instituições é praticamente nulo. O que importa ao analista é saber quais as preferências existentes na sociedade. As instituições apenas processam estas preferências de forma neutra, retornando decisões de acordo com a correlação de forças dos interesses existentes na sociedade. Para os Novos Institucionalistas as instituições têm papel autônomo, próprio. Não apenas "induzem" ao equilíbrio, como também têm influência direta na determinação do resultado político substantivo. (LIMONGI 1994, p. 9).
}

Para o autor, os neoinstitucionalistas levam em conta a importância das instituições nas análises dos processos legislativos, mas não se preocupam em fazer uma formulação precisa a respeito das instituições. O que há é a sugestão de regras, leis, procedimentos, 
VALLE, M. V. T. Abordagem ao neoinstitucionalismo e seus desdobramentos nas análises que se apresentam nos estudos sobre o Legislativo Municipal

normas, arranjos institucionais e organizacionais que influenciam a existência de constrangimentos e limites ao comportamento do parlamentar. Esse tipo de sugestão serve como forma de análise para o comportamento legislativo. A ideia de instituição, contudo, acaba permanecendo genérica.

Neste momento, apresentamos os modelos que fazem parte do paradigma neoconstitucionalista, sendo o primeiro chamado de distributivista, por ocorrer "em função da distribuição de votos nos municípios do Estado, o que determina diferentes condutas na disputa eleitoral e comportamentos legislativos distintos, consoante o perfil do legislador" (AMES 2003).

Para Nelson Carvalho (2003 p. 20-21), o uso de tal modelo é importante para interpretar o comportamento legislativo brasileiro e que se deu em função de alguns elementos análogos aos presentes no Congresso estadunidense, como: a) a baixa institucionalização dos partidos; b) o particularismo legislativo; e, sobretudo, c) o predomínio do voto personalizado na arena eleitoral. $\mathrm{O}$ autor ainda ressalta que as "diferentes estratégias decorrem dos diversos tipos de relacionamento dos legisladores com suas bases".

Esse aspecto faz alusão ao que o autor destaca sobre a importância da "conexão eleitoral" na estratégia política do legislador, ou seja, a relação entre representado e representante faz com que todo parlamentar tenha fortes incentivos para atender aos interesses específicos dos eleitores de sua região. Para ele, uma política distributiva se constitui em uma decisão de política que concentra benefícios em um distrito geográfico específico e financia gastos por meio de uma tributação generalizada. Esse tipo de política traz uma incidência geográfica de custos e benefícios, e o que distingue uma política distributiva é que os benefícios têm um alvo geograficamente definido (CARVALHO 2003, p. 20).

Segundo a análise neoinstitucionalista, os parlamentares agem de forma individual, sendo suas ações utilizadas para alcançar o resultado esperado, que no caso é a reeleição. Isso é um elemento motivacional para agirem na arena legislativa. Porém, o Legislativo é marcado por disputas e conflitos atrelados a diversos interesses individuais e de grupos. Assim, as atribuições que mais se destacam entre os parlamentares são a formulação e a destinação de recursos e benefícios voltados para suas bases eleitorais.

De acordo com Neves (2010), Ames e Mainwaring (quando analisaram o sistema partidário brasileiro) identificaram um grau mínimo de institucionalização a partir da fragilidade do sistema político-partidário, em que os partidos se caracterizaram por serem fracos e indisciplinados no parlamento. Isso acarretaria uma paralisia e um entrave ao avanço da democracia. Nesse caso, os autores levaram em conta a teoria distributiva, destacando o 
comportamento individualista dos atores políticos relacionado com uma conexão eleitoral, o que resulta em um atomismo parlamentar em prejuízo de qualquer tipo de organização e centralização partidária. Nesse sentido, os parlamentares buscariam a maximização dos interesses particulares em detrimento dos constrangimentos institucionais, visando livremente aos redutos paroquiais.

Limongi (1994) chama a atenção para o fato de que a hegemonia do modelo distributivista foi abalada, formando-se duas tendências a partir dela. A primeira foi a formação da vertente informacional, que parte do princípio de que as instituições estão articuladas aos apelos do Poder Legislativo, e suas decisões estão relacionadas com um grande número de informação disponível. O Congresso tem o papel motivacional de transformar os congressistas em especialistas em determinadas áreas políticas, disponibilizando o uso das informações de forma benéfica para todos.

Já o modelo partidário se constitui por uma perspectiva diferente e crítica ao modelo distributivista. Ressalta a importância dos partidos políticos como elementos imprescindíveis da atividade legislativa, ou seja, há forte influência dos partidos nas atividades legislativas. Isso porque as regras legislativas e os procedimentos de tomada de decisão estão relacionados com uma atuação partidarizada, e a composição das comissões parlamentares também está associada à disputa entre os partidos governistas e de oposição. Com isso, as decisões acabam sendo tomadas de acordo com a orientação partidária, e não individual. Silva (2013), ao citar Lima Junior, chama atenção que esse modelo partidário leva a uma perspectiva endógena, em termos de análise, sobre o comportamento parlamentar, que pode ser verificado pelas seguintes palavras:

\footnotetext{
Ao endogenizar a instituição legislativa, permite-se que ela passe a ser "variável independente", tendo em vista o comportamento do congressista e os resultados (outcomes) do processo legislativo. Ademais, a própria organização interna da instituição passa a constituir uma escolha para os legisladores. [...] Os estudos sobre o Poder Legislativo têm mostrado a centralidade da organização interna para a compreensão dos resultados gerados pelo sistema político como um todo, em que pese a importância do padrão de relação entre os Poderes Executivo e Legislativo. (LIMA JUNIOR 1999, p. 39-41 apud SILVA 2013, p. 8).
}

Essa perspectiva endógena de análise levou a considerar a instituição legislativa como variável independente. Lima Junior (1999) chama a atenção para a mudança na forma de se abordarem os temas que envolvem os partidos políticos de acordo com o desenvolvimento de pesquisas sobre instituições e sistemas político, eleitoral e partidário.

Santos (2008) identificou diferentes variáveis que se formaram com o desenvolvimento do neoinstitucionalismo e os diversos métodos de análise do Legislativo 
VALLE, M. V. T. Abordagem ao neoinstitucionalismo e seus desdobramentos nas análises que se apresentam nos estudos sobre o Legislativo Municipal

brasileiro. O levantamento feito por ele procurou reunir os estudos feitos de 1994 a 2005 sobre o Congresso Nacional. São apresentadas as variáveis explicativas, que se dividem em endógenas e exógenas à instituição legislativa.

Quadro 1 - Variáveis exógenas explicativas da organização do Legislativo brasileiro

\begin{tabular}{|c|c|}
\hline $\begin{array}{c}\text { Macrovariáveis } \\
\text { Agregação de variáveis } \\
\text { explicativas (questão central) }\end{array}$ & Conjunto de variáveis (operacionalização) \\
\hline $\begin{array}{l}\text { Federalismo } \\
\text { Conjunto de variáveis relativas às } \\
\text { tensões intergovernamentais } \\
\text { (governo central versus níveis } \\
\text { subnacionais de governo) e } \\
\text { relativas ao poder dos } \\
\text { governadores sobre as bancadas } \\
\text { estaduais }\end{array}$ & $\begin{array}{l}\text { Distribuição de recursos orçamentários (investimentos e } \\
\text { transferências constitucionais); distribuição de recursos por meio } \\
\text { de empréstimos do FGTS (transferências não constitucionais); } \\
\text { execução de emendas orçamentárias das bancadas dos estados; } \\
\text { governador forte ou fraco eleitoralmente; reeleição do governador; } \\
\text { voto da bancada dos estados em questões relativas à redefinição } \\
\text { do pacto federativo; convênios entre ministérios e prefeituras. }\end{array}$ \\
\hline $\begin{array}{l}\quad \text { Forma de governo } \\
\text { Variáveis relativas à forma de } \\
\text { governo }\end{array}$ & $\begin{array}{l}\text { Parlamentarismo versus presidencialismo, em especial aspectos } \\
\text { relativos às características do presidencialismo brasileiro. }\end{array}$ \\
\hline $\begin{array}{l}\frac{\text { Sistema eleitoral }}{\text { Conjunto de variáveis }} \\
\text { relativas às regras eleitorais e } \\
\text { partidárias }\end{array}$ & $\begin{array}{l}\text { Sistema de lista aberta; processo de escolha dos candidatos no } \\
\text { interior do partido; descentralização da escolha dos candidatos no } \\
\text { partido; migração partidária (fidelidade); magnitude do distrito; } \\
\text { competição eleitoral no distrito; gastos de campanha; número de } \\
\text { cadeiras do distrito; desproporcionalidade (número de cadeiras } \\
\text { versus número de habitantes - malappointment); eleição em dois } \\
\text { turnos para governadores (indica fraqueza ou força do } \\
\text { governador); ciclos eleitorais. }\end{array}$ \\
\hline $\begin{array}{l}\text { Desempenho eleitoral } \\
\text { Conjunto de variáveis relativas ao } \\
\text { desempenho eleitoral do } \\
\text { parlamentar e de seu padrão de } \\
\text { votação nos distritos }\end{array}$ & $\begin{array}{l}\text { Número de votos; padrão de votação (dominante/compartilhada e } \\
\text { dispersa/concentrada); padrão de coalizões com os atores políticos } \\
\text { locais (coalizão com o governador e o prefeito); independência } \\
\text { (do deputado diante de seus concorrentes no mesmo município); } \\
\text { desempenho eleitoral dado por sua posição na lista; margem de } \\
\text { vitória na última eleição. }\end{array}$ \\
\hline
\end{tabular}

Fonte: Extraído de Barbosa (2014b) que apresenta as variáveis explicativas da Organização do Legislativo Brasileiro. Baseado no artigo de Manoel Leonardo Santos. Teoria e Método nos Estudos Sobre Legislativo Brasileiro: uma revisão da literatura no período de 1994/2005. BIB, São Paulo, n. 66, $2^{\circ}$ Semestre de 2008, pp. 65-89.

Quadro 2 - Variáveis endógenas explicativas da organização do Legislativo brasileiro

\begin{tabular}{|c|l|}
\hline $\begin{array}{c}\text { Macrovariáveis. } \\
\text { Agregação de variáveis } \\
\text { explicativas (questão central) }\end{array}$ & \multicolumn{1}{|c|}{ Conjunto de variáveis (operacionalização) } \\
\hline $\begin{array}{c}\text { Poderes do presidente } \\
\text { Variáveis relativas aos poderes de } \\
\text { que dispõe o presidente para fazer } \\
\text { valer sua vontade sobre o } \\
\text { Legislativo }\end{array}$ & $\begin{array}{l}\text { Iniciativa exclusiva de leis, decretos com força de lei - } \\
\text { medidas provisórias; requerimento de urgência; poder de veto. }\end{array}$ \\
\hline $\begin{array}{c}\text { Centralização decisória } \\
\text { Conjunto de variáveis que } \\
\text { determina o processo decisório } \\
\text { centralizado ou descentralizado }\end{array}$ & $\begin{array}{l}\text { Poderes concentrados no colégio de líderes (poder de agenda; } \\
\text { requerimento de urgência; negociações privilegiadas); poderes } \\
\text { dos líderes partidários (encaminhamento de votações } \\
\text { nominais; voto de liderança; controle da apresentação de }\end{array}$ \\
\hline
\end{tabular}




\begin{tabular}{|c|c|}
\hline no Legislativo & $\begin{array}{l}\text { emendas em plenário); Poder Legislativo pleno das comissões } \\
\text { permanentes. }\end{array}$ \\
\hline $\begin{array}{l}\text { Direitos parlamentares } \\
\text { Variáveis relativas à distribuição } \\
\text { de direitos parlamentares e de } \\
\text { recursos legislativos }\end{array}$ & $\begin{array}{l}\text { Ocupar o cargo de liderança do partido; liderança de bancada; } \\
\text { mesa diretora; designação para as comissões permanentes para } \\
\text { as CPIs e comissões especiais; indicação para presidência das } \\
\text { comissões; indicação para relatorias. }\end{array}$ \\
\hline $\begin{array}{l}\text { Partidos políticos } \\
\text { Conjunto de variáveis relativas ao } \\
\text { poder do partido político na arena } \\
\text { parlamentar }\end{array}$ & $\begin{array}{l}\text { Partidos fortes (com capacidade para resolver problemas de } \\
\text { ação coletiva); partidos fracos (que não desempenham um } \\
\text { papel relevante na arena legislativa); migração partidária; } \\
\text { coesão partidária; disciplina partidária. }\end{array}$ \\
\hline $\begin{array}{l}\text { Patronagem } \\
\text { Conjunto de variáveis relativas à } \\
\text { distribuição de recursos por parte } \\
\text { do Executivo com o objetivo de } \\
\text { formar coalizões no parlamento } \\
\text { em favor de sua agenda política }\end{array}$ & $\begin{array}{l}\text { Nomeações no gabinete; distribuição do orçamento por } \\
\text { ministério a partir dos critérios partidários; efetiva execução } \\
\text { (valor) das emendas orçamentárias dos parlamentares; decurso } \\
\text { (diminuição do interesse pela patronagem e afastamento da } \\
\text { coalizão presidencial em virtude do final do mandato do } \\
\text { presidente); recompensa (número de ministérios proporcional } \\
\text { ao número de cadeiras do partido); coalescência (índice } \\
\text { indicativo do grau de coerência entre a formação do gabinete e } \\
\text { a proporcionalidade partidária no parlamento); concessão de } \\
\text { rádio e TV. }\end{array}$ \\
\hline $\begin{array}{l}\text { Processo legislativo } \\
\text { Conjunto de variáveis relativas às } \\
\text { regras de tramitação e ao tipo de } \\
\text { proposição e seus impactos nos } \\
\text { outcomes legislativos }\end{array}$ & $\begin{array}{l}\text { Tipo de proposição (decreto legislativo; projeto de lei, medida } \\
\text { provisória, projetos de resoluções etc.); tempo de tramitação; } \\
\text { autoria (autor na liderança dos partidos ou em cargos de } \\
\text { destaque no parlamento); sede da revisão final (casa); parecer } \\
\text { técnico das comissões (favorável ou contrário); relatoria. }\end{array}$ \\
\hline
\end{tabular}

Fonte: Extraído de Barbosa (2014b) que apresenta as variáveis explicativas da Organização do Legislativo Brasileiro. Baseado no artigo de Manoel Leonardo Santos. Teoria e Método nos Estudos Sobre Legislativo Brasileiro: uma revisão da literatura no período de 1994/2005. BIB, São Paulo, n. 66, $2^{\circ}$ Semestre de 2008, pp. 65-89.

De acordo com Barbosa, para os que procuram ressaltar uma abordagem endógena, os representantes atuam no Legislativo conforme "a estrutura de centralização decisória do Congresso e com uma organização partidária igualmente centralizada junto aos líderes partidários, e ao poder do Executivo brasileiro" (BARBOSA 2014b, p. 19). Ainda sobre a perspectiva endógena, Barbosa (2014b) destaca uma afirmação de Santos, segundo a qual: “[...] a tese desse grupo é orientada pela assunção de que as instituições próprias do Poder Legislativo (e da sua relação com o Executivo) importam e têm impacto tanto na organização quanto na performance e no conteúdo dos outcomes legislativos)" (SANTOS 2008, p. 8 apud BARBOSA 2014b, p. 19).

Para Barbosa (2014b), a relação entre o Executivo e o Legislativo é de fundamental importância para a compreensão da organização do Legislativo brasileiro. As variáveis que se destacam nesse modelo são as prerrogativas constitucionais, que conferem poderes ao presidente da República (LIMONGI 2006; SANTOS 2002).

Devemos ressaltar também que esses trabalhos procuraram abordar a dimensão institucional como uma referência — levando em consideração as relações entre o Executivo 
VALLE, M. V. T. Abordagem ao neoinstitucionalismo e seus desdobramentos nas análises que se apresentam nos estudos sobre o Legislativo Municipal

e o Legislativo - na correlação de forças partidárias e institucionais no interior do Legislativo, além da dimensão institucional desses poderes, o que significa falar de governabilidade da casa legislativa e dos partidos políticos. Os autores, de forma geral, postulam suas análises a partir de uma perspectiva teoricamente híbrida, atribuindo importância fundamental ao aspecto institucional, sem deixar de perceber seu conjunto, sobretudo na perspectiva da conexão eleitoral, da patronagem e de outras formas de disputa por recursos distributivos, além da relevância do elemento partidário.

Verificaremos esses aspectos na seção seguinte, quando faremos uma análise descritiva do Legislativo no nível municipal de governo. Isso no sentido de identificar os estudos sobre a Câmara Municipal que utilizem a abordagem neoinstitucionalista.

\section{UMA ABORDAGEM DO NEOINSTITUCIONALISMO NOS ESTUDOS SOBRE O LEGISLATIVO MUNICIPAL NO BRASIL}

Nesta seção, pretendemos analisar a influência do neoinstitucionalismo e a forma como é apresentada nos estudos que abordam o Poder Legislativo na esfera municipal do Brasil.

Primeiramente, destacamos um aspecto abordado por Silva (2013) sobre a influência do neoinstitucionalismo que serviu de base para pesquisar o Legislativo municipal e suas peculiaridades. Assim, Torrens (2015 p. 3) ressalta que tanto as Câmaras municipais quanto os vereadores passaram a ter papel significativo do ponto de vista político-institucional, formando-se, consequentemente, estudos voltados para:

(a) O comportamento dos vereadores nas Câmaras Municipais;

(b) O papel desempenhado pelos partidos políticos no processo decisório local e na articulação das lideranças locais;

(c) Os aspectos gerais do processo legislativo, como as regras de tramitação dos projetos, a utilização de dispositivos legislativos que não gerem leis, o uso de emendas nos projetos, a atividade das comissões permanentes e o tempo de tramitação das proposições;

(d) As negociações envolvendo aspectos fundamentais da relação entre Executivo e Legislativo locais;

(e) As dinâmicas existentes entre arena de governo e arena eleitoral.

A partir desses elementos, apresentamos alguns estudos acadêmicos, dissertações e artigos sobre o Legislativo municipal brasileiro e a relação com o Executivo local, como os trabalhos citados por Barbosa (2014b): Ruggiero Junior (2005), Lopez (2004), Almeida e 
Lopez (2011, 2012), D’Ávila, Jorge e Lima (2010, 2011, 2014), Felisbino (2009), Caetano (2005), Praça e Garcia (2011), Kerbauy (2004), Silva (2011), Raupp (2012) e Sabbado (2010). Para Barbosa (2014b), esses trabalhos indicam que o poder local, no Brasil, se caracteriza por ter:

(a) A preponderância do Executivo sobre o Legislativo;

(b) O Legislativo frágil, que pouco segue os deveres de fiscalização do Executivo;

(c) O Legislativo que se propõe mais a um assistencialismo, prestação de serviços, do que a criação de leis — produção legislativa;

(d) Os partidos fracos;

(e) $\mathrm{O}$ forte apelo à conexão eleitoral.

Os autores desses trabalhos desenvolveram seus estudos a partir da análise da atuação do vereador no que tange às seguintes ações: "propostas de projetos de leis, sugestão de emendas e assistencialismos informais" (BARBOSA 2014b, p. 9). No entanto, poucas pesquisas têm dado importância a outros dispositivos parlamentares formais, como "elaboração de indicações, requerimentos e moções" (BARBOSA, 2014b, p. 9), que fazem parte do cotidiano dos vereadores em seu mandato municipal; assim, ainda segundo o trabalho de Barbosa (2014b), destacamos as pesquisas de D’Ávila Filho, Lima e Jorge (2010, 2011), Silva (2013) e Lopez (2004).

Ressaltamos também que essas proposições "não possuem efeito de lei, mas contam como produção do parlamentar, somando, na maioria das Câmaras Municipais, o maior volume de produção parlamentar dos vereadores" (SILVA 2013, p. 2). Esses dispositivos são enormemente utilizados no âmbito do município por causa das restrições que há no âmbito do Legislativo municipal, impedindo o vereador de exercer o que, supomos, deveria ser sua principal função: legislar, ou seja, criar projetos de leis. O trabalho de D’Ávila Filho, Lima e Jorge nos oferece a explicação do pouco interesse dos cientistas políticos brasileiros pela esfera municipal. Isso se deve, segundo esses autores, às

[...] dificuldades dos vereadores em produzir legislação local significativa, diante dos constrangimentos impostos pelas Constituições Federais e Estaduais, restando pouca margem para a criatividade dos vereadores [...]. Diante das razões que este autor expressa como causadoras da lacuna sobre os estudos do legislativo municipal. (D'ÁVILA FILHO; LIMA; JORGE 2010, p. 3).

Apesar dos trabalhos supracitados, não são muitos os estudos sobre municípios no Brasil. Isso ocorre porque a ciência política brasileira, de modo geral, tem privilegiado dois recortes. Primeiro, porque as análises das unidades subnacionais têm focado os Legislativos 
VALLE, M. V. T. Abordagem ao neoinstitucionalismo e seus desdobramentos nas análises que se apresentam nos estudos sobre o Legislativo Municipal

estaduais. Segundo, porque, quando se voltaram para os municípios, a atenção foi dada aos principais municípios das regiões Sul e Sudeste do país; mais precisamente, às capitais e aos municípios de grande porte dessas regiões. Isso se verifica nas palavras de Kerbauy quando afirma que

[...] não há muitos trabalhos que abordam a atuação do Legislativo municipal, às regras que determinam o processo de interação dos Poderes Executivo e Legislativo, às formas como se orientam as ações dos atores políticos do Legislativo local e ao papel desempenhado pelo sistema eleitoral e partidário, e pelas eleições, nas Câmaras Municipais. Os estudos feitos analisam em geral o Legislativo das capitais dos estados (COUTO, 1998; MELO, 2005; BRUNO, 2005; TEIXEIRA, 2000; SERTZLER, 2000). Sobre municípios de pequeno e médio porte, destacam-se as contribuições de Carneiro e Almeida (2005), Jofre (2003), D'Ávila Filho (2004) e Souza (2004). (KERBAUY 2014, p. 2).

Assim, Rocha e Kerbauy (2014) entendem que os estudos legislativos no Brasil avançaram bastante em termos teóricos e metodológicos. Apesar de a Constituição de 1988 ter dado ao município o status de ente federativo autônomo, isso não foi suficiente para despertar o interesse dos cientistas políticos brasileiros pela representação política e pelo processo legislativo no nível municipal. Essa continua sendo, portanto, uma lacuna quando se considera seu status na atual ordem constitucional brasileira. Acreditamos que a ausência de um número expressivo de trabalhos - de boa qualidade - sobre o poder municipal e, em particular, do Poder Legislativo municipal dificulte nossa compreensão da política brasileira.

Em seu trabalho sobre o poder local, Rocha e Kerbauy (2014) analisam a representação política em nível municipal a partir da organização partidária, da competição eleitoral e do processo de produção de políticas públicas associadas a um conjunto de questões. As autoras ressaltam que a influência dos partidos políticos na arena eleitoral e parlamentar nos variados municípios é uma incógnita quando se refere à política local. A formação de diferentes estruturas partidárias ou de subsistemas partidários indica uma variabilidade entre o Executivo e o Legislativo nos municípios e estados brasileiros. De acordo com as autoras, por haver diferentes contextos, há uma dificuldade em transplantar padrões que se apresentam em nível nacional para níveis subnacionais.

Rocha e Kerbauy (2014) ainda ressaltam que o exercício da representação política em nível local se atrela a uma relação marcada pelo clientelismo. De acordo com as autoras, nessa arena, o tipo de relação estabelecido entre representantes e representados seria marcado pela "lógica da relação pessoal, com pouca, ou quase nenhuma, mediação dos partidos políticos” (ROCHA; KERBAUY 2014, p. 4). 
Para Souza (2004), por exemplo, as transferências de recursos individuais garantem a reeleição dos vereadores, levando a um círculo vicioso, que se apresenta na política local, baseado no clientelismo, no mandonismo, no paternalismo e na hegemonia do Poder Executivo, com relações de dependência político-partidária dos governos locais para com os governos estaduais. Contudo, Kebauy ressalta que há a necessidade de se avançar, buscando outras formas de compreensão do comportamento dos atores políticos locais, em particular dos membros do Legislativo (KERBAUY 2005, p. 339).

Uma importante contribuição teórico-metodológica para o estudo do poder municipal foi dada por D’Ávila Filho, Lima e Jorge. Em trabalho publicado recentemente acerca do Poder Legislativo na esfera municipal, esses autores adotaram a seguinte perspectiva em relação à ideia de representação política em nível local:

\footnotetext{
Na perspectiva que estamos adotando, a questão em torno do significado da representação afasta-se do dever ser canônico e normativo que marca os preceitos constitucionais ou o debate teórico da área. Encontramo-nos no âmbito do que poderíamos chamar de "representações sobre a ideia de representação". Para além do debate normativo em torno do significado da representação e dos arranjos institucionais ou regras que poderiam levar-nos a uma suposta melhor representação, nosso estudo concentra-se no que chamamos de "representações em uso" em clara alusão à ideia clássica de "linguagem em uso" de Wittgenstein (1994), tão bem explorada por MacIntyre (1991). (D'ÁVILA FILHO; LIMA; JORGE 2014, p. 40)
}

A partir disso, ao elaborar um levantamento sobre a literatura do Legislativo municipal, Barbosa (2013) ressalta os trabalhos de Ruggiero Junior (2005) sobre a cidade de Araraquara (SP), que visa compreender a relação entre Legislativo e Executivo em momentos distintos (1997-2000 e 2001-2004) no que tange aos projetos de leis ordinárias. Sua conclusão é de que houve um aumento significativo de poder e controle do Executivo da agenda legislativa nos dois períodos.

Outros trabalhos também apontam a preponderância do Executivo sobre o Legislativo em nível municipal. Lopez (2004) estudou o cotidiano do vereador em uma cidade do Rio Janeiro, Araruama, pela abordagem da antropologia política. Esse autor concluiu que, de modo geral, os Legislativos têm se mostrado mais fracos do que os Executivos municipais, os primeiros com atuação fraca e baixa capacidade de legislar. Felisbino (2009), por sua vez, após estudar a relação entre Executivo e Legislativo no município de Mogi-Mirim (SP) (1960-1963 e 1997-2000), também chegou à conclusão de que, nesse município paulistano, a Casa Legislativa era subordinada ao Poder Executivo por causa de recursos que este último tem antes e após a redemocratização (BARBOSA 2013, p. 4-5). 
VALLE, M. V. T. Abordagem ao neoinstitucionalismo e seus desdobramentos nas análises que se apresentam nos estudos sobre o Legislativo Municipal

Ao relacionarmos a teoria neoinstitucionalista com o comportamento legislativo em nível local, podemos citar a perspectiva de Ames (2003) de que as instituições políticas criam incentivos para estimular os políticos a maximizarem seus ganhos pessoais e a se concentrarem em obter projetos de obras públicas para eleitores localizados. Nesse caso, o Legislativo municipal seria o exemplo mais extremado dessa situação, ao exagerar a orientação individualista e fisiológica desempenhada pelos vereadores em detrimento do impacto dos partidos políticos na arena eleitoral local. Já aplicação dos modelos teóricos do neoinstitucionalismo nas análises do Legislativo municipal, de acordo com Rocha e Kerbauy (2014), fica limitada por causa de um problema de escala das cidades e também da inexistência de dados e informações dos diferentes municípios que permitam um estudo comparativo entre eles. Segundo a legislação eleitoral, o número de vereadores é proporcional ao número de habitantes do município. Quanto ao número de municípios e suas características no Brasil, Kerbauy destaca que:

O Brasil possui 5.563 municípios dos quais 1.363 foram criados a partir de
1989, graças às regras flexíveis estabelecidas pelo artigo 18, $\S 4$ o, da
Constituição de 1988 definidas para preservar "a continuidade e unidade
histórico-cultural do ambiente urbano, obedecidos os requisitos previstos em
lei complementar estadual e mediante consulta prévia às populações
diretamente envolvidas". O resultado visível do aumento do número de
municípios na última década é o fato de $90 \%$ deles terem menos de 50 mil
habitantes e $80 \%$ de suas despesas serem cobertas por transferências
institucionais. (KERBAUY 2005, p. 338).

Também devemos destacar Caetano, que chama a atenção para a aproximação dos estudos sobre o poder local com o presidencialismo brasileiro, que "faz com que os Poderes Executivo e Legislativo sejam regidos por soberanias paralelas, que não regem incentivos à cooperação" (CAETANO 2005, p. 107). Isso leva o sistema proporcional de lista aberta a contribuir para fragilizar os partidos brasileiros e incentivaria ações individuais por parte dos atores políticos (BARBOSA 2014a, p. 5). O autor identifica isso como um problema que se estabelece em nível municipal. Também demonstra o quanto a Câmara Municipal de São Paulo é bem centralizada, aproximando-se do modelo partidário. O prefeito da cidade paulista tem um poder de influência nos trabalhos legislativos, respaldado pelo Regimento Interno e pela Lei Orgânica do Município.

Já o estudo de Silva (2011) demonstrou que as apresentações dos projetos de leis dos vereadores tinham uma característica voltada para a distribuição generalizada no município mais do que em suas bases paroquiais. Esse fato aponta para um afastamento da hipótese distributivista. Isso se verifica a partir da aplicação do conceito de pork barrel, associado a 
uma política voltada para agradar determinadas zonas geográficas onde geralmente estão situados os eleitores que premiam ou não os políticos. Para Barbosa (2014a), pork barrel é uma medida localizada intencionalmente na espera de retornos eleitoreiros. Estaria circunscrito à hipótese da conexão eleitoral no comportamento dos legisladores na atuação das câmaras. $\mathrm{O}$ autor demostrou empiricamente que os votos que os vereadores receberam nos dois anos de competição eleitoral — 2000 e 2004 — têm caráter mais disperso do que concentrado, pois a elevada competição eleitoral que se apresenta no município de São Paulo impede os candidatos de focalizar somente uma região específica (BARBOSA 2014a, p. 7).

Os trabalhos de Garcia (2013), Ferreira e Pralon (1998) e Couto (1998), que abordam a perspectiva distributiva, se relacionam com os Poderes Executivo e Legislativo, ressaltam que a conjuntura política determina a relação entre os poderes e isso leva os parlamentares a obter recursos com o objetivo de favorecer suas bases eleitorais. Esses trabalhos também procuram analisar a Câmara Municipal de São Paulo.

Não podemos esquecer a pesquisa de Carvalho sobre as Câmaras Municipais da Região Metropolitana do Rio de Janeiro, na qual o autor também adota o distributivismo para verificar

[...] a ênfase no curso do mandato a atividades de casework de natureza assistencialista. Mandatos que se sustentam e se renovam com base em centros sociais parecem se constituir, assim, numa forma extrema de especialização nesse tipo de atividade. Atividade que se processa por fora dos canais do Legislativo e, muitas vezes, prescinde do Executivo. (CARVALHO 2010, p. 5).

Para o autor, a ação de legislar em importantes áreas da política - como uso do solo, tributos e transportes - é deixada de lado pelos vereadores, que a colocam a cargo do Executivo, e a modalidade de legislação acaba se restringindo às indicações que se apresentam de forma distributivista.

\section{CONSIDERAÇÕES FINAIS}

Devemos chamar atenção de que os trabalhos apresentados formam uma diversidade de análises, deixando os termos município ou política municipal vagos (ROCHA; KERBAUY 2014). Quando as autoras se referem a essa imprecisão sobre os municípios, estão levando em conta a grande variedade de municípios no Brasil, pois seu tamanho acaba determinando as diversas explicações sobre o comportamento do parlamentar. A relação entre o porte do município e os indicadores socioeconômicos (taxas de urbanização como índice de 
VALLE, M. V. T. Abordagem ao neoinstitucionalismo e seus desdobramentos nas análises que se apresentam nos estudos sobre o Legislativo Municipal

desenvolvimento urbano) também determina a importância dos estudos sobre a política local. O tamanho do município acaba sendo fundamental para estabelecer análises de estratégias sobre alinhamentos partidários que se formam em níveis estadual e federal. Isso se torna algo desafiante para os pesquisadores.

Pelo exposto, Rocha e Kerbauy (2014) destacam os métodos e as técnicas utilizados para analisar o comportamento legislativo em âmbito local, como a pesquisa etnográfica e a observação participante, a aplicação de surveys, entrevistas, pesquisa documental, entre outros. Além de dialogar com diferentes perspectivas teóricas e metodológicas, esses recursos se constituem em uma forma de superar as dificuldades que se apresentam para o entendimento da representação política e os estudos legislativos na esfera municipal.

Dessa forma, as futuras pesquisas poderão considerar esses aspectos apontados pelas autoras, na medida em que a esfera municipal acaba sendo uma instituição relevante para o desenvolvimento de pesquisas sobre o comportamento parlamentar.

\section{REFERÊNCIAS BIBLIOGRÁFICAS}

ALMEIDA, D. R. 2008. Representação política: reflexões a partir da prática da sociedade civil nos conselhos de políticas. In: $32^{\circ}$ ENCONTRO ANUAL DA ANPOCS. Anais... Caxambu.

ALMEIDA, M. H. T.; CARNEIRO, L. P. C. 2003. Liderança local, democracia e políticas públicas no Brasil. Opinião pública, Campinas, vol. IX, n. 1, p. 124-147.

ALMEIDA, Acir; LOPEZ, Félix. Representação Política Local: padrões de atuação dos vereadores em quatro cidades mineiras. IPEA, Brasília, 1625, p. 1- 44, 2011.

AMES, B. 2003. Os entraves à democracia no Brasil. Rio de Janeiro: FGV.

ANASTASIA, F. 1997. Transformando o Legislativo: a experiência da Assembleia Legislativa de Minas Gerais. In: O Poder Legislativo nos Estados: diversidade e convergência. Org. Fabiano Santos. Editora FGV, Rio de Janeiro, 2001.

BARBOSA, A. R. 2013. Um estudo sobre a utilização dos projetos de indicações na Câmara municipal de Salvador. In: III FÓRUM BRASILEIRO DE PÓS-GRADUAÇÃO EM CIÊNCIA POLÍTICA. Anais... Curitiba: UFPR, 31 jul./2 ago.

A. R. 2014a. As abordagens metodológicas das recentes pesquisas sobre os estudos legislativos nos municípios brasileiros. In: QUINTO CONGRESO URUGUAYO DE CIENCIA POLÍTICA, “QQUÉ CIENCIA POLÍTICA PARA QUÉ DEMOCRACIA?”. Anais... Uruguai: Asociación Uruguaya de Ciencia Política, 7-10 out. 
2014b. Relação Executivo-Legislativo e Produção parlamentar na Câmara Municipal de Salvador. Dissertação de aprovada em, 06 de março de 2014, para obtenção do título de Mestre em Ciências Sociais.

CARVALHO, N. R. 2003. E no início eram as bases: geografia política do voto e comportamento legislativo no Brasil. Rio de Janeiro: Revan.

N. R. 2010. Localismos, geografia social do voto e governança metropolitana. Rio de Janeiro: Observatório das Metrópoles.

COUTO, C. G. 1998. Negociação, decisão e governo: padrões interativos na relação Executivo-Legislativo e o caso paulistano. In: ANDRADE, R. de C. (Org.). Processo de governo no município e no Estado. São Paulo: Universidade de São Paulo.

D’ÁVILA, P.; JORGE, V. L., LIMA, P. C. G. C. 2010. Produção legislativa e intermediação de interesses na Câmara Municipal do Rio de Janeiro. In: VII ENCONTRO DA ABCP. Anais... Recife: ABCP. p. 2-24.

D’ÁVILA, P.; JORGE, V. L., LIMA, P. C. G. C. 2011. Produção legislativa na Câmara Municipal do Rio de Janeiro: indicações, representação política e intermediação de interesses. Desigualdade \& diversidade, PUC-RJ, volume especial, p. 185-206.

D’ÁVILA, P.; JORGE, V. L., LIMA, P. C. G. C. 2014. Indicação e intermediação de interesses: uma análise da conexão eleitoral na cidade do Rio de Janeiro, 2001-2004. Rev. sociol. polit., v. 22, n. 49, p. 39-60, mar.

FERREIRA, G.; PRALON, E. 1998. Centralidade na Câmara Municipal de São Paulo no Processo Decisório. In: ANDRADE, Regis de Castro (org). Processo de governo no município e no estado: uma análise a partir de São Paulo. São Paulo: Editora USP, p. 73-86.

FELISBINO, R. A. 2009. Atores e práticas na relação Executivo-Legislativo municipal: o caso do município de Mogi-Mirim (SP) em dois contextos democráticos (1946-1964 e pós1988). Revista omnia humanas, v. 2, n. 1, p. 27- 47, jan./jun.

GARCIA, J. G. 2013. Executivo e Legislativo no âmbito municipal: a formação de gabinetes no município de São Paulo (1989-2012). 2013. 51 f. Dissertação (Mestrado em Administração Pública e Governo)- Escola de Administração de Empresas de São Paulo da Fundação Getulio Vargas, São Paulo.

HALL, P.; TAYLOR, R. C. R. 2003. As três versões do neo-institucionalismo. Lua nova, São Paulo, n. 58, p. 123-223.

KERBAUY, M. T. M. 2004. Descentralização, processo decisório e políticas públicas locais. Estudos de sociologia, Araraquara, n. 16, p. 151-163.

KERBAUY, M. T. M. 2005. As Câmaras Municipais brasileiras: perfil de carreira e percepção sobre o processo decisório local. Opinião pública, Campinas, v. 2, p. 337-365. 
VALLE, M. V. T. Abordagem ao neoinstitucionalismo e seus desdobramentos nas análises que se apresentam nos estudos sobre o Legislativo Municipal

KERBAUY, M. T. M. 2014. Organização partidária e elites parlamentares municipais. In: XII BRAZILIAN STUDIES ASSOCIATION (BRASA). Londres. Sessão Política Local no Brasil.

LIMA JR., O. B. 1999. Partidos, eleições e Poder Legislativo. In: MICELI, S. (Org.). O que ler na ciência social brasileira (1970-1995). São Paulo: Sumaré/Anpocs; Brasília: Capes.

LIMONGI, F. 1994. O novo institucionalismo e os estudos legislativos: a literatura norteamericana recente. $B I B$, n. 37 , p. 3-38.

2006. A Democracia no Brasil: Presidencialismo, coalizão partidária e processo decisório. Novos Estudos, nº 76, Nov., p. 17-41.

LIMONGI, F.; FIGUEIREDO, A. C. 2004. Modelos de Legislativo: o legislativo brasileiro em perspectiva. Revista plenarium, ano I, n. 1, nov.

LOPEZ, Felix G. 2004. A política cotidiana dos vereadores e as relações entre executivo e legislativo em âmbito municipal: o caso do município de Araruama. Rev. Sociologia e Política, Curitiba, 22, 153-177.

MAINWARING, S. 1991. Políticos, partidos e sistemas eleitorais: o Brasil numa perspectiva comparada. Novos estudos Cebrap, n. 29.

MAINWARING, S. 2001. Sistemas partidários em novas democracias: o caso do Brasil. Tradução de Vera Pereira. Porto Alegre: Mercado Aberto; Rio de Janeiro: FGV.

MORAIS, T. F. 2008. Neoinstitucionalismo e o sistema político brasileiro. In: XVI SEMANA DE HUMANIDADES - GT 32 - DEMOCRACIA, PARTIDOS POLÍTICOS E COMPORTAMENTO ELEITORAL, 2008, Rio Grande do Norte. Anais... Rio Grande do 204 Revista de Informação Legislativa Norte: UFRN.

NEVES, C. A. 2010. Geografia do voto e conexão eleitoral nas eleições de 1994 a 2006 para deputado federal no Piauí. Teresina. Dissertação (mestrado). Universidade Federal do Piauí.

PRAÇA, S.; GARCIA, J. 2011. Formação de governo no nível municipal: o caso dos municípios paulistas. In: Encontro Anual da ANPOCS, 35º Águas de Lindóia. Anais... Águas de Lindóia, São Paulo: ANPOCS, p. 1-18.

RAUPP, F. 2012. Ensaio teórico sobre a presença do patrimonialismo no poder legislativo local. XV SEMEAD - Seminários em Administração. São Paulo: Programa de Pós Graduação - FEA USP. ISSN 2177- 3866, p.1-16.

ROCHA, M. M.; KERBAUY, M. T. M. 2014. Eleições, partidos e representação política nos municípios brasileiros. Juiz de Fora: UFJF.

RUGGIERO JR., N. 2005. A atuação do vereador na Câmara Municipal de Araraquara: processo legislativo em dois momentos. São Carlos. Dissertação (mestrado) (Mestre em ciências sociais). Centro de Educação em Ciências Humanas. Universidade Federal de São Carlos. 
SABBADO, L. S. 2010. Poder de agenda em esfera local: uma análise comparada da produção legislativa de dois governos de Pelotas, RS (2001-2008). 219 f. Pelotas. Dissertação (Mestrado em C. Sociais) - Instituto de Sociologia e Política, Universidade Federal de Pelotas, Rio Grande do Sul.

SANTOS, F. 1997 A Dinâmica Legislativa no Estado do Rio de Janeiro: Análises de uma Legislatura. O Poder Legislativo nos Estados: diversidade e convergência. Org. Fabiano Santos. Editora FGV, Rio de Janeiro, 2001.

2002. Partidos e comissões no presidencialismo de coalizão. Rio de Janeiro:

DADOS, vol.45, n.2, p.237-264.

SANTOS, M. L. 2008. Teoria e método nos estudos sobre o Legislativo brasileiro: uma revisão da literatura no período 1994-2005. BIB, São Paulo, n. 66, p. 65-89, 2. semestre.

SILVA, B. S. 2013. Legislativos municipais: balanço da produção recente na ciência política brasileira e suas implicações metodológicas. In: III FÓRUM BRASILEIRO DE PÓSGRADUAÇÃO EM CIÊNCIA POLÍTICA. In: Anais... Curitiba: UFPR, 31 jul./2 ago.

SILVA, P. 2011. O pork barrel no Município de São Paulo: a produção legislativa dos vereadores paulistanos. Centro de Estudos da Metrópole (CEM), São Paulo, p. 1-25.

SOUZA, R. B. 2004. Clientelismo e voto na Califórnia fluminense. In: 28ํㅡㄹ ENCNTRO ANUAL DA ANPOCS. Anais... Caxambu.

TORRENS, A. C. 2015. A Câmara Municipal de Curitiba e labor legislativo: as interfaces da representação política. Curitiba. Tese (doutorado) (Doutor em Ciências Sociais). Programa de Pós-graduação em Sociologia. Departamento de Ciências Sociais. Universidade Federal do Paraná. 